\title{
Information Analysis and Forecasting of the Deals in the Business Utilizing Prediction Model
}

\author{
Vinod Kadam ${ }^{a}$, Sangeeta Vhatkar ${ }^{b}$ \\ Thakur College of Engineering and Technology, Kandivali(E), Mumbai-400101, India ${ }^{\mathrm{a}}$ \\ kadamvinod52@gmail.com ${ }^{\mathrm{a}}$, vhatkarsangeeta@gmail.com ${ }^{\mathrm{b}}$
}

\begin{abstract}
Information Analysis and Forecasting on Supermarket Sales Transactions is a proposed framework which centre around the improvement of the deals in the business. The entire proposed framework includes generally of 4 areas: Exploratory Data Analysis in bits of knowledge, exploratory data assessment is an approach to manage separating enlightening assortments to gather their rule credits, consistently with visual methods. Exploratory Data Analysis proposes the fundamental technique for performing starting appraisals on information to find plans, to spot anomalies, to test hypothesis and to check questions with the help of framework estimations and graphical depictions. Client Segmentation Theoretically it will have sections like Low Value: Customers who are less dynamic than others, not extremely incessant purchaser/guest and creates low - zero - perhaps adverse income. Mid Value: in all things. Consistently using our establishment (anyway not whatever amount of our High Values), really nonstop and makes moderate pay. High Value: The social event it would not really like to lose. High Revenue, Frequency and low Inactivity. Market Basket Analysis is a methodology which recognizes the nature of connection between sets of things purchased together and perceive instances of cooccasion. A co-occasion is when at any rate two things happen together. Time-arrangement strategies for estimating. Gauging is a methodology or a proposed framework for assessing predetermination parts of a business undertaking or the interest. It's far a technique for unravelling past realities or experience into esteem judgments of what might be on the horizon.
\end{abstract}

Keywords: Apriori Algorithm, Arima, Market Basket Analysis, RFM model, Sarima, Time series

\section{Introduction}

Information analysis and forecasting on supermarket sales transactions which centre around the advancement of the deals in the business. As of now noticing strong results from associations that use Machine Learning (ML) just as Artificial Intelligence (AI) to outperform their resistance and close more plans. Truth be told, outreach groups that embrace these devices are seeing an in drives what's more, plans of over half and cost lessens of up to $60 \%$, as appeared by the Harvard Business Review. Here are only a couple of the conceivable outcomes like decipher client information, Improve deals guaging, anticipate client needs, Efficient exchange deals. For information examination, It's from the start handle the data. So In Statistics, EDA (exploratory information investigation) is utilized to: Better comprehend the information, fabricate an instinct about the information, create theory, discover bits of knowledge, Visualization. After the picturing the information utilized RFM(recency, recurrence, financial) examination to section the client. The RFM model estimates when individuals buy(Recency), how frequently they buy(Frequency) and the amount they buy(Monetary). While past procurement of customer can feasibly anticipate their future purchase lead, association can recognize which customer is admirable. To figure RFM model score we will apply K-mean bunching. Regardless, It ought to instruct the number concerning bunches we need to K-suggests computation. To find it out, we will apply Elbow Method. Elbow Method simply tells the ideal gathering number for ideal torpidity. For better comprehension of the outcome we can see the mean worth of Recency, Frequency and Revenue address. With we can section the information on the channel of low-esteem, mid-worth and high- 
International Journal of Intelligent Communication, Computing and Networks

Open Access Journal (ISSN: 2582-7707)

https://doi.org/10.51735/ijiccn/001/22

esteem. After RFM Score we need to distinguishes the strength of relationship between sets of item bought together and recognize examples of co-event, for that we use Market Basket Analysis(MBA). A co-occasion is when at any rate two things happen together. For advantageous result in MBA we measure the energy of a standard by means of computing the ensuing lattices like Support, Confidence and lift. After MBA we break down deals exchange information for item racking by Apriori Algorithm [1] Time arrangement is a technique for guaging. At this moment deciphering past data or experience into check of what might be on the horizon. As a result of the occasional design of time arrangement utilized, the occasional arima (sarima) is picked for the model development [2].

\subsection{Introduce the Problem}

The present questionable economy, organizations are attempting to receive elective approaches to stay serious. Distinctive incapable determining strategies lead to various item stock outs. So research revolves around (company size, stakeholders, solutions they want) different forecasting techniques for demand prediction through machine learning have the ability to compare it to historical sales efforts. The proposed framework can come to an obvious conclusion and better foresee what arrangements would be viable and the probability of the arrangement shutting and to what extent it will take. This understanding enables deals the executives to more readily apportion assets and anticipate deals projections.

\section{Proposed Methodology}

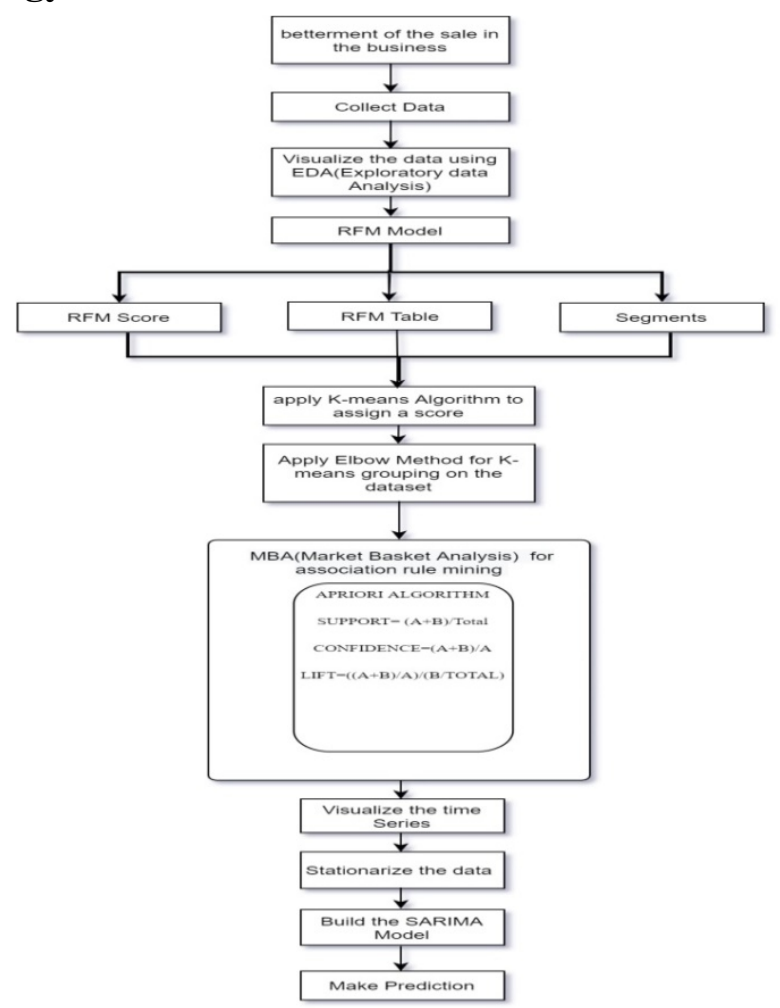

Figure 1: Data Analysis and Forecasting Architecture 
International Journal of Intelligent Communication, Computing and Networks

Open Access Journal (ISSN: 2582-7707)

https://doi.org/10.51735/ijiccn/001/22

\section{Discussion}

\subsection{Exploratory Data Analysis(EDA)}

In EDA(exploratory information examination) the primary sign that a perception is acceptable is that it shows you an issue in your information, recognize exceptions or abnormal occasions and discover fascinating relations among the factors. A factual variant can be utilized or now not, however basically EDA is for seeing what the data can educate us past the common appearance or theory looking at proposed System.

\subsection{RFM(Recency, Frequency, Monetary) Model}

For a productive business, partaking in an amazing fight is a critical task for promoters. Generally, promoters ought to at first recognize feature division using a logical mode and a short time later execute a powerful fight expect to target productive customers. Proposed framework was relied upon to utilized RFM(recency, recurrence, money related) idea to portion client. RFM technique is accustomed to examining client esteem. It is by and large used in information base advancing and direct promoting and has gotten explicit thought in retail and master organizations ventures [3]. This examination proposes using the going with RFM factors:

- $\quad \operatorname{Recency}(\mathrm{R})$ : when people buy.

- $\quad$ Frequency(F): how often they buy.

- $\quad \operatorname{Monetary}(\mathrm{M})$ : how much they buy.

\subsection{Market Basket Analysis(MBA)}

Market Basket Analysis(MBA) is a common instance of affiliation rule mining. Market Basket Analysis makes If-Then circumstance rules, for example, if thing An is gained, by then thing B is presumably going to be purchased. The norms are probabilistic in nature or, in a manner of speaking, they are gotten from the frequencies of co-occasion in the discernments. Among all of the systems for data mining, apriori calculation is viewed as better for affiliation rule mining [4].

The critical thought in the Apriori calculation is that it acknowledges all subsets of an unending itemset to be visit. Additionally, for any rare itemset, all its super-sets should likewise be inconsistent. To choose the intriguing guidelines out of different potential standards from the business, proposed framework is utilizing the accompanying measures:

Support: The essential measure called the assistance is the amount of trades that recollect things for the $\{A\}$ and $\{B\}$ parts of the norm as a level of the hard and fast number of trades. It is an extent of the amount of the time the arrangement of things happen all together things being what they are.

Support $=(\mathrm{A}+\mathrm{B}) /$ Total 
International Journal of Intelligent Communication, Computing and Networks

Open Access Journal (ISSN: 2582-7707)

https://doi.org/10.51735/ijiccn/001/22

Confidence: The comprehension of the normal, worn out is the extent of the amount of trades that comprise of all devices in $\{\mathrm{B}\}$ notwithstanding the assortment of exchanges that envelop all things in $\{A\}$ to the quantity of exchanges that remember all things for $\{A\}$.

Confidence $=(\mathrm{A}+\mathrm{B}) / \mathrm{A}$

Lift: The third measure called the lift or lift extent is the extent of certainty to expected certainty. Expected conviction is the certainty isolated by the repeat of B. The Lift uncovers to us how much better a standard is at expecting the result than just tolerating the result regardless. More prominent lift esteems show more grounded affiliations.

$\mathrm{Lift}=((\mathrm{A}+\mathrm{B} / \mathrm{A}) /(\mathrm{B} /$ Total $))$

\subsection{Time Series Forecasting}

Time-arrangement techniques for anticipating. Gauging(Forecasting) is a procedure or a path for evaluating predetermination components of a business or the leisure activity. It is a methodology for deciphering past records or experience into tests of what might be on the horizon.

Time arrangement involves the utilization of records which are recorded through similarly separated additions of time (mins, hours, days, weeks, etc.). On account of the discrete thought of time plan data, many time course of action educational records have an ordinary or conceivably design segment fused with the data. Stage one in time arrangement demonstrating is to represent ebb and flow seasons (a repetitive example throughout a set time-frame) as well as moves vertically (or descending development inside the insights). Addressing these embedded models is what we call making the data fixed. Arrangement is supposed to be fixed arrangement if and just if the joint likelihood is doesn't change over the long haul that is the mean and fluctuation of the arrangement stay consistent after some time. With slanting data, as time increase the mean of the affiliation either augments or reduces with time (consider the consistent augmentation in housing costs sooner or later). For seasonal(everyday) records, the mean of the course of action sways as in sync with the season (ponder thought on the expansion and diminishing in temperature as expected).

$\mathrm{F}=(\mathrm{Yt})=\mathrm{F}(\mathrm{Yt}+\mathrm{k})$

There are two methodologies that might be applied to accomplish stationarity, contrast the measurements or straight relapse. To take a qualification, you ascertain the distinction among sequential perceptions. To apply direct relapse, you incorporate twofold marker factors for your occasional thing in the mode Auto-backward fused moving normal or arima, is a determining strategy for univariate time assortment realities. Auto-backward and moving normal variables. The incorporated component alludes to separating permitting the way to deal with help time arrangement realities with a pattern. A problem with arima is that it doesn't help occasional records. That could be a period arrangement with a rehashing cycle. Arima expects realities this is both not occasional or has 
International Journal of Intelligent Communication, Computing and Networks

Open Access Journal (ISSN: 2582-7707)

https://doi.org/10.51735/ijiccn/001/22

the occasional thing taken out, for example Occasionally changed through systems comprehensive of occasional differencing. SARIMA strategy is time arrangement guaging technique for stochastic model information with occasional information pattern [5].

- $\quad \operatorname{ARIMA~(p,~d,~q):~The~non-seasonal~part~of~the~model~}$

- $\quad$ SARIMA notation is $(\mathrm{P}, \mathrm{D}, \mathrm{Q}) \mathrm{s}$ : The seasonal part of the model

- $\quad$ s: Seasonal factor

Seasonal(Regular) Autoregressive coordinated moving normal, sarima or occasional arima, is a choice of arima that unequivocally reinforces uni-variate time game plan realities with an intermittent stage. It adds three new hyper boundaries to indicate the auto regression (ar), differencing (I) and moving normal (mama) for the occasional thing of the arrangement, notwithstanding an additional boundary over the span of the seasonality [6].

\section{Results}

Dataset Understanding:

Table 1: Sale transactional data of the time period of December 2010 to December 2011

\begin{tabular}{|c|c|c|c|c|c|c|c|}
\hline $\begin{array}{c}\text { Invoice } \\
\text { Date }\end{array}$ & $\begin{array}{c}\text { Stock } \\
\text { Code }\end{array}$ & Description & Quantity & $\begin{array}{c}\text { Invoice } \\
\text { Date }\end{array}$ & $\begin{array}{c}\text { Unit } \\
\text { Price }\end{array}$ & $\begin{array}{c}\text { Customer } \\
\text { ID }\end{array}$ & Country \\
\hline 536365 & $85123 \mathrm{~A}$ & $\begin{array}{c}\text { WHITE HANGING } \\
\text { HEART TLIGHT } \\
\text { HOLDER }\end{array}$ & 6 & $\begin{array}{c}2010-12-01 \\
08: 26: 00\end{array}$ & 2.55 & 17850.0 & $\begin{array}{c}\text { United } \\
\text { Kingdom }\end{array}$ \\
\hline 536365 & 71053 & $\begin{array}{c}\text { WHITE METAL } \\
\text { LANTERN }\end{array}$ & 6 & $\begin{array}{c}2010-12-01 \\
08: 26: 00\end{array}$ & 3.39 & 17850.0 & $\begin{array}{c}\text { United } \\
\text { Kingdom }\end{array}$ \\
\hline 536365 & $84029 \mathrm{G}$ & $\begin{array}{c}\text { KLAG HOT WATER } \\
\text { BOOTTLE }\end{array}$ & 6 & $\begin{array}{c}2010-12-01 \\
08: 26: 00\end{array}$ & 3.39 & 17850.0 & $\begin{array}{c}\text { United } \\
\text { Kingdom }\end{array}$ \\
\hline 536365 & 22752 & $\begin{array}{c}\text { SET 7 BABUSHKA } \\
\text { NESTING BOXES }\end{array}$ & 2 & $\begin{array}{c}2010-12-01 \\
08: 26: 00\end{array}$ & 7.65 & 17850.0 & $\begin{array}{c}\text { United } \\
\text { Kingdom }\end{array}$ \\
\hline 536366 & 22633 & $\begin{array}{c}\text { HAND WARMER } \\
\text { UNION JACK }\end{array}$ & 6 & $\begin{array}{c}2010-12-01 \\
08: 28: 00\end{array}$ & 1.85 & 17850.0 & $\begin{array}{c}\text { United } \\
\text { Kingdom }\end{array}$ \\
\hline 536366 & 22632 & $\begin{array}{c}\text { HAND WARMER } \\
\text { RED POLKA DOT }\end{array}$ & 6 & $\begin{array}{c}2010-12-01 \\
08: 28: 00\end{array}$ & 1.85 & 17850.0 & $\begin{array}{c}\text { United } \\
\text { Kingdom }\end{array}$ \\
\hline 536367 & 84879 & $\begin{array}{c}\text { ASSORTED COLOUR } \\
\text { BIRD ORNAMENT }\end{array}$ & 32 & $\begin{array}{c}2010-12-01 \\
08: 34: 00\end{array}$ & 1.69 & 17850.0 & $\begin{array}{c}\text { United } \\
\text { Kingdom }\end{array}$ \\
\hline
\end{tabular}

Table 2: Invoice Year Month

\begin{tabular}{|l|l|}
\hline Invoice Year Month & Revenue \\
\hline 201012 & 748957.020 \\
\hline 201101 & 560000.260 \\
\hline 201102 & 498062.650 \\
\hline 201103 & 683267.080 \\
\hline 201104 & 493207.121 \\
\hline 201105 & 723333.510 \\
\hline 201106 & 691123.120 \\
\hline 201107 & 681300.111 \\
\hline
\end{tabular}


International Journal of Intelligent Communication, Computing and Networks Open Access Journal (ISSN: 2582-7707)

https://doi.org/10.51735/ijiccn/001/22

\begin{tabular}{|l|l|}
\hline 201108 & 682680.510 \\
\hline 201109 & 1019687.622 \\
\hline 201110 & 1070704.670 \\
\hline
\end{tabular}

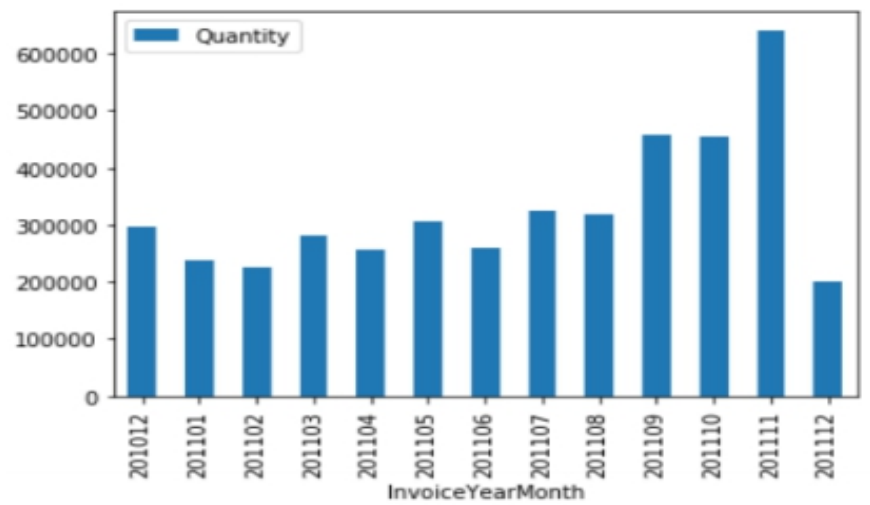

Figure 2: Monthly order count by using quantity field.

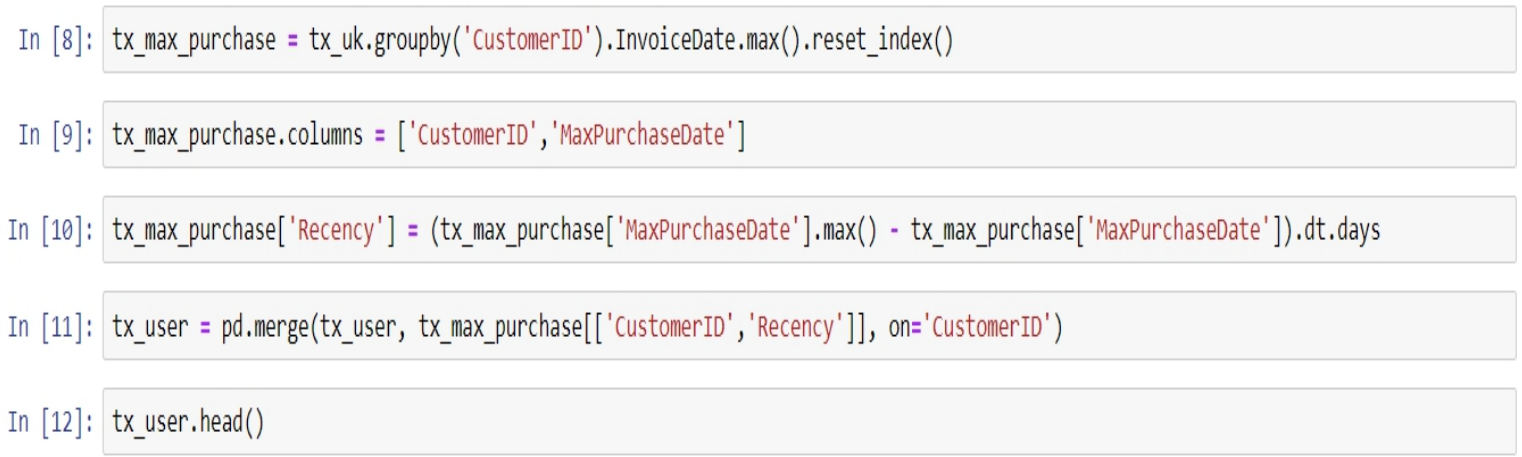

Figure 3: Calculating Recency for each customer.

Table 3: Calculating Recency for each month

\begin{tabular}{|l|l|}
\hline Customer ID & Recency \\
\hline 17850.0 & 301 \\
\hline 13047.0 & 31 \\
\hline 13748.0 & 95 \\
\hline 15100.0 & 329 \\
\hline 15291.0 & 25 \\
\hline
\end{tabular}

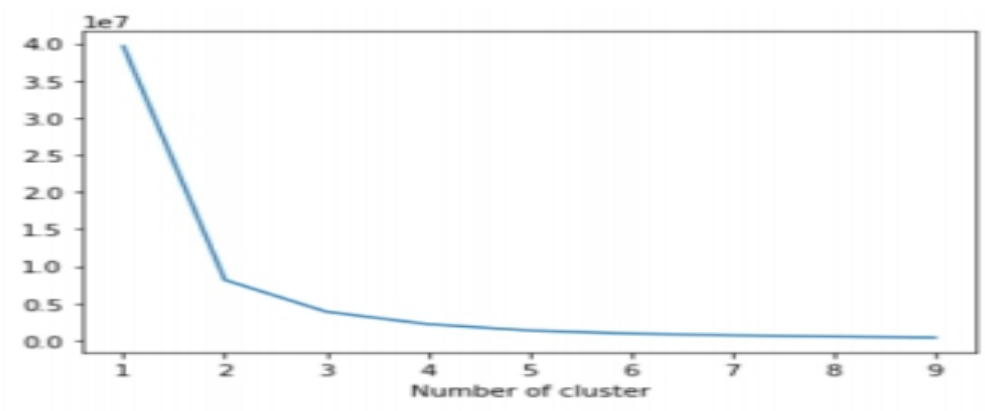

Figure 4: Calculating Recency for each customer. 
International Journal of Intelligent Communication, Computing and Networks Open Access Journal (ISSN: 2582-7707)

https://doi.org/10.51735/ijiccn/001/22

Table 4: The mean value of Recency, Frequency and Revenue

\begin{tabular}{|c|c|c|c|}
\hline Overall Score & Recency & Frequency & Revenue \\
\hline 0 & 304.584388 & 21.995781 & 303.339705 \\
\hline 1 & 185.362989 & 32.596085 & 498.087546 \\
\hline 2 & 78.991304 & 46.963043 & 868.082991 \\
\hline 3 & 20.689610 & 68.419590 & 1091.416414 \\
\hline 4 & 14.892617 & 271.755034 & 3607.097114 \\
\hline 5 & 9.662162 & 373.290541 & 9136.946014 \\
\hline 6 & 7.740741 & 876.037037 & 22777.914815 \\
\hline 7 & 1.857143 & 1272.714286 & 103954.025714 \\
\hline 8 & 1.333333 & 5917.666667 & 42177.930000 \\
\hline
\end{tabular}
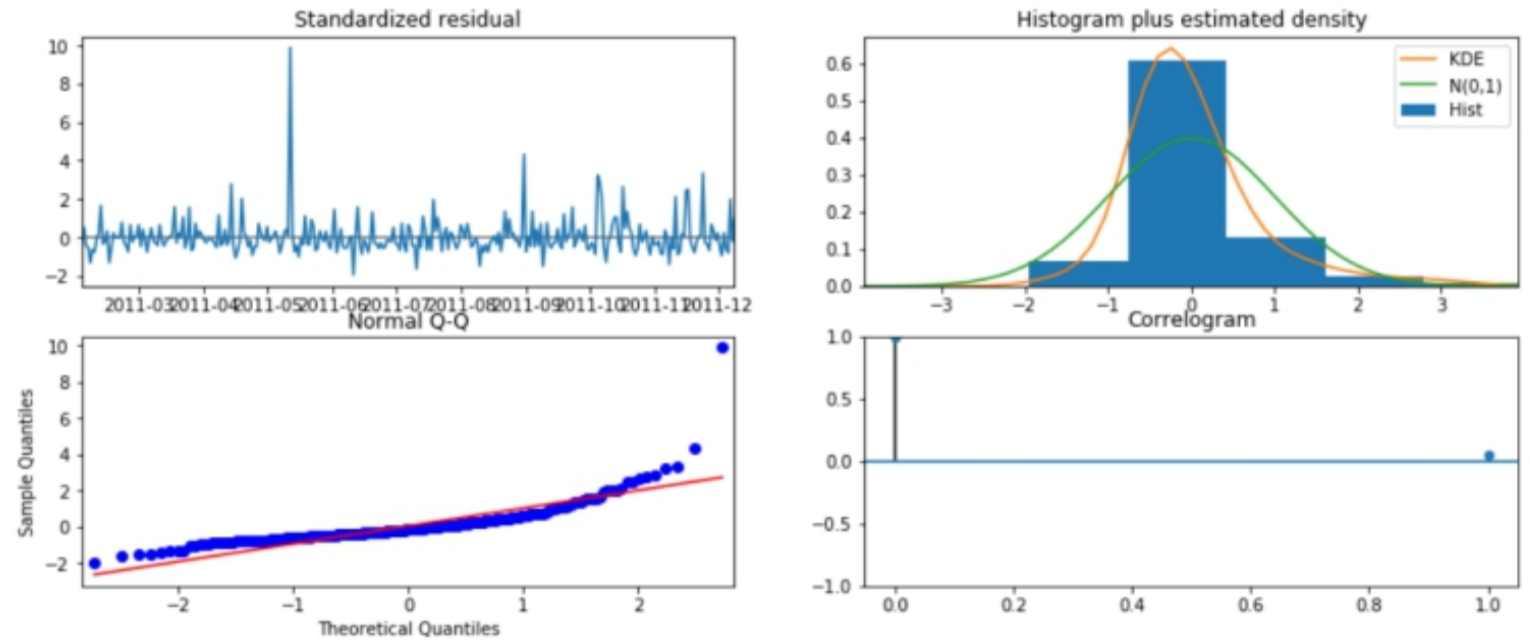

Figure 5: Time Series Forecasting of Germany

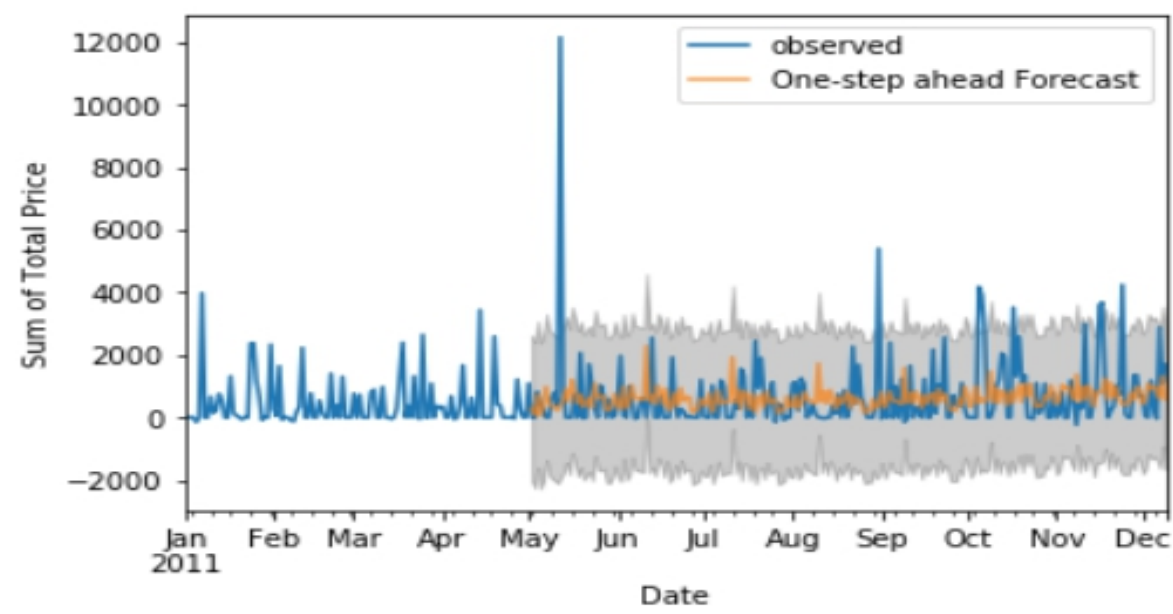

Figure 6: One Step ahead forecast on the Germany data.

Note. One step ahead forecast utilizes the real incentive for each ensuing estimate. The Mean Squared Error of our forecasts is 1607357.8 . 


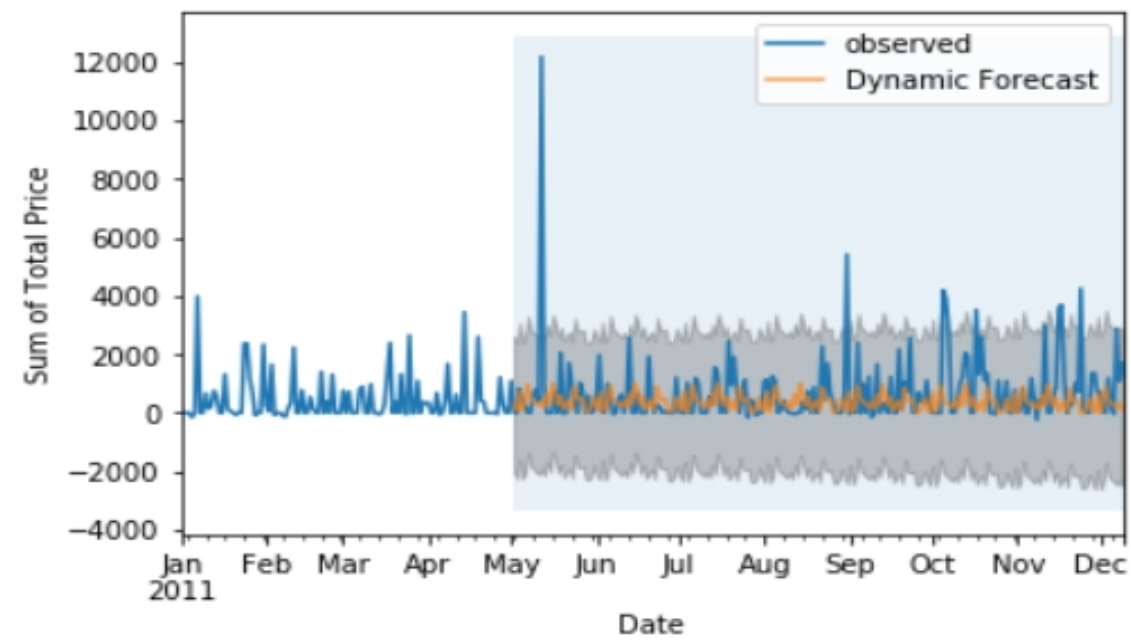

Figure 7: One Step ahead forecast on the Germany data.

Note. Dynamic forecast utilizes the estimation of the past forecasted estimation of the reliant variable to register the following one. The Mean Squared Error of our forecasts is 1648114.76.

\section{Conclusion}

This paper depicts the system of Forecasting exhaustively. In encounters, EDA is a way to deal with oversee isolating instructive combinations to sum up their standard credits, reliably with visual strategies. It is insinuate performing early on assessments on data to discover plans, to spot peculiarities, and to check speculation with the help of summery bits of knowledge and graphical depictions. There is a better understanding on which customers are priority and which are not and have better understanding what action are required on low priority customer to improve sales. It would seem that 3 is the ideal one dependent on business necessities. We can proceed with less or more bunches. Now its shows products are mostly bought in pairs, which can enable the business at store level to sell these product side by side in store to improve furthermore sales. further this model was regularized, market basket analysis on France from the Dataset then use these finding to improve sales by pairing up the frequent bought items together. The precision of the regularized model was discovered to be in the sell 340 Green Alarm tickers yet just 316 Red Alarm Clocks. so perhaps it can drive more Red Alarm Clock deals through proposals. Accordingly it is presumed that SARIMA gives precise consequences of figures and can be utilized for foreseeing the deals of store on Germany information utilizing One stride ahead conjecture of genuine incentive for each ensuing estimate and the Mean Squared Error of our gauges is 1607357.8. At that point Dynamic estimate utilizes the estimation of the past gauge estimation of the reliant variable to figure the following one. The Mean Squared Error of our conjectures is 1648114.76. In spite of the fact that picking of the model for determining will absolutely rely upon the kind of dataset.

\section{Future Scope}

We can see the future trends with the help of time series forecasting of each and every county and understand which country need more attention in terms of improving sales in the coming near future. The current data set spans over a year, on getting the entire up to date data we can get more reverent analysis to the current time. With such huge data we can make a more accurate time series prediction for better understanding of the trends of 
International Journal of Intelligent Communication, Computing and Networks

Open Access Journal (ISSN: 2582-7707)

https://doi.org/10.51735/ijiccn/001/22

the Future. The knowledge of the store in each country, if attended we can classify them on performance and your key metric being sales. More targeted analysis can be archive.

\section{References}

1. Komal Nain Sukhia, Aliya Ashraf Khan, Mukhtiar Bano: Introducing Economic Order Quantity Model for Inventory Control in Web based Point of Sale Applications and Comparative Analysis of Techniques for Demand Forecasting in Inventory Manage-ment International Journal of Computer Applications (0975 - 8887) Volume 107 - No. 19, December 2014.

2. Adhistya Erna Permanasari, Indriana Hidayah, Isna Alfi Bustoni: SARIMA (Seasonal ARIMA)

Implementation on Time Series to Forecast The Number of Malaria Incidence, Indonesia (2016).

3. XIONG Weiwen, CHEN Liang, ZHANG Zhiyong, QIU Zhuqiang: RFM Value and Grey Relation Based Customer segmentation Model in the Logistics Market Segmentation, 2008 International Conference on Computer Science and Software Engineering, China.

4. Dr. M. Dhanabhakyam, Dr. M. Punithavalli: A survey on data mining algorithm for Market basket analysis, Global Journal of Computer Science and Technology Volume 11 Issue 11 Version 1.0 July 2011 Type: Double Blind Peer Reviewed International Research Journal Publisher: Global Journals Inc. (USA) Online ISSN:

0975-4172 \& Print ISSN: 0975.

5. GAN Pongdatu, Y H Putra: Seasonal Time Series Forecasting using SARIMA and Holt.

6. Winter's Exponential Smoothing, Magister of Information System, Faculty of Postgrad-uate, Universitas Komputer Indonesia, 112-116 Jalan Dipatiukur, Lebak Gede, Coblong, Bandung, Jawa Barat, 40132, Indonesia, 2018. 